\title{
Group training in interpersonal problem-solving skills for workplace adaptation of adolescents and adults with Asperger syndrome. A preliminary study.
}

\author{
Saray Bonete ${ }^{1,2}$, María Dolores Calero ${ }^{1}$, Antonio Fernández-Parra ${ }^{1}$ \\ ${ }^{1}$ University of Granada, (Spain) \\ ${ }^{2}$ Universidad Francisco de Vitoria, (Spain)
}

Corresponding author: Saray Bonete, Universidad Francisco de Vitoria, Ctra. Pozuelo-Majadahonda Km. 1.800, 28223 Pozuelo de Alarcón, Madrid, Spain. Email: s.bonete.prof@ufv.es

\section{Acknowledgments}

This project was partially supported by the University of Granada FPU Plan Propio grant. We are grateful to the participants, their parents and staff from the following associations who cooperated in the study: Asociación Asperger Madrid, Asociación Asperger Granada, Centro Hans Asperger Sevilla, Asociación Asperger ASPALI and Asociación Asperger Valencia. We also thank Mariana Ciuffreda for her help with the English translation. This project was approved by the Ethics Commitee of the University of Granada.

\section{Conflict of Interest}

The authors declare that we have no conflict of interest. 
Group training in interpersonal problem-solving skills for workplace adaptation of adolescents and adults with Asperger syndrome. A preliminary study.

\begin{abstract}
Adults with Asperger Syndrome show persistent difficulties in social situations which psychosocial treatments may address. Despite the multiple studies focusing on social skills interventions little have focused specifically on problem-solving skills and have not targeted workplace adaptation training in the adult population. This study describes preliminary data from a group format manual-based intervention, the Interpersonal Problem-Solving for Workplace Adaptation (SCI-Labour) Programme, aimed at improving the cognitive and metacognitive process of social problem-solving skills focusing on typical social situations in the workplace based on mediation as the main strategy. Fifty adults with Asperger syndrome received programme and were compared with a control group of typical development. The feasibility and effectiveness of the treatment were explored. Participants were assessed at pre-treatment and post-treatment on a task of social problem-solving skills and two secondary measures of socialisation and work profile using self- and caregiver-report. Using a variety of methods, the results showed that scores were significantly higher at post-treatment in the social problemsolving task and socialisation skills based on reports by parents. Differences in comparison to the control group had decreased after treatment. The treatment was acceptable to families and subject adherence was high. SCI-Labour Programme appears to be a feasible training programme.
\end{abstract}

\title{
Keywords
}

Autism Spectrum Disorders, Group Intervention, Social Problem-Solving Training, Asperger Syndrome, Adults, Workplace Adaptation 
Nuclear symptoms in Asperger syndrome (AS) amount to an altered social development, characterised by a severe deficit in reciprocal social skills or socialisation. Although this condition is expressed differently in each person, it appears in three main areas; social interaction, communication skills and stereotyped patterns of behaviour, restricted interests and/or rigid adhesion to routines without cognitive or language retardation (APA, 2000; Carter et al. 2005).

Social deficits in adults with Autism Spectrum Disorders (ASD) may lead to problems concerning important areas of quality of life such as friendship, romantic relationships and vocational success. In recent years, there has been increasing recognition of the need to carry out studies to ascertain the effectiveness and efficacy of different types of intervention and programmes aimed at training or improving pragmatics, social communication and interpersonal skills - the main areas affected in AS individuals. Recent decades have provided improved scientific knowledge on early infancy and there is now an urgent need to focus on adolescents and adults (Mazefsky and White, 2013). In fact, most of the studies have been conducted with school-age children (Maddox and White, in press). A growing body of papers is being published concerning adolescents and adults with ASD although research on the feasibility and efficacy of social interventions for adults is limited (Baron-Cohen et al., 2004; Gantman et al., 2012; Laugeson et al., 2012; White et al., 2012).

In psychology, the literature on social skills is extensive, although there are different approaches and backgrounds (psychometric perspective, clinical psychology, educational area, cognitive psychology, etc). Three main approaches could be distinguished in classifying social skill interventions developed for ASD depending 
where the focus is allocated: 1) Increasing positive behaviours (discrete skills) in social situations (Hops, 1983) such as the PEERS Programme (Chang et al., 2013; Laugeson et al., 2012) which aims at teaching specific behaviours that facilitate positive social interactions. 2) Cognitive restructuring for social skills or cognitive-behavioural approach (Weiss and Lunsky, 2010). One example is the MASSI programme (White et al., 2012) simultaneously targeting anxiety management and social skills. 3) Improving interpersonal (cognitive) problem-solving skills which are considered a domain of intelligence. Special emphasis is put on the cognitive processes of problem resolution that could be trained (Chang et al., 2009; Leshner et al., 2013). This approach highlights the importance of the role that others play in an interaction where ethical issues are integrated and need to be dealt with (Nezu et al., 2008; Pelechano, 1995). Despite being highly applicable in daily life interaction there is not an extensive literature on this matter for ASD (Soloman et al., 2004; Antshel et al., 2011).

Based on this perspective of interpersonal problem-solving skills training, we developed and evaluated the Interpersonal Problem-Solving Skills for Workplace Adaptation (SCI-Labour) Programme [Programa de Solución de Conflictos Interpersonales] in this trial. To the authors' knowledge, no study to date has evaluated the effectiveness of interpersonal problem-solving skills training for adolescents and adults with AS focusing on typical social situations in the workplace.

The SCI-Labour programme is based on an approach called social problemsolving in phases (D'Zurilla and Goldfriend, 1971; Pelechano, 1995) as the cognitive process involved is based on phases of resolution such as: problem definition, taking perspectives, generating solutions and considering consequences. The methodological strategy to implement the programme is mediation (Haywood and Lidz, 2007). 
Mediated learning assumes that during the learning process someone more competent than the trainee is tasked with selecting the relevant stimuli to address and emphasise, provide continuous feedback based on the trainee's answers and change and interpret the environment to facilitate the learning process (Kozulin and Rand, 2000; Tzuriel, 2000). It is believed that this approach is suitable for the ASD population in adulthood as it provides training on a thinking process that could be applied to different contexts (i.e. workplace environment). The latest reviews on aging in ASD (Anderson et al., 2013; Happé and Charlton, 2012; Howlin and Moss, 2012; Parr and Hunter, 2013) emphasise the frequently reported problems with employment in adults with ASD.

Although individuals with AS may possess the technical skills required for a job, they may not be able to engage in reciprocal conversation or think and quickly respond to questions during a job interview. Despite the potential to work, few persons with AS are in regular em- ployment, and those who are employed find their employment levels disappointing and their occupational status low. Many times jobs end prematurely, often leading to low self-esteem and depression

Inability to maintain employment due to poor social commu- nication between employee and employer or coworkers, social skills deficits, and sensory issues were the biggest problems cited by adults with AS who were interviewed by Hurlbutt and social training awareness and instruction on the unwritten rules of the workplace; and development of an effective working relationship between the employee and the

People with ASD are significantly disadvantaged regarding employment due to challenges that may present at work which have been describe in the literature on ASD: difficulties in communication, problems in response shifting and adapting to change and sensitivity to sensory stimuli (Parr \& Hunter, 2013). Some of the obstacles employees 
with ASD face at work include difficulties in communication, problems in response shifting and adapting to change, and sensitivity to sensory stimuli (Hendricks, 2010). If ignored, these obstacles may ultimately create a barrier to effective performance at work. Therefore,

Despite claims for the need of a wider database on vocational skills and employment in ASD (Garcia-Villamisar and Huges, 2007; Hare et al., 2004; Hillier et al., 2007; Morgan and Schultz, 2012), intervention research in social skills has not specifically focused on workplace adaptation.

This programme was first implemented in a pilot study for four adolescents ( 3 men and a woman) with Asperger syndrome between the ages of 16 and 21 years. Two of the four showed significant positive results in a social problem-solving task and parents reported improvements in socialisation skills (Bonete, 2013). After the pilot study, some changes were made to the manual programme resulting in the final version of the SCI-Laboral Programme.

The purpose of the present study was to further develop and assess the effectiveness and feasibility of a manualised interpersonal problem-solving training programme (SCI-Labour) oriented to Asperger syndrome adolescents and adults. Effectiveness refers to the measurement of improvement in the specific skills that appear after a psychosocial intervention implemented in community settings (Smith et al., 2007). Feasibility has been defined as evidence that the treatment can be reliably delivered and is acceptable to the patient population (Kraemer et al., 2006). Following the stepwise approach to the development, testing, and dissemination of psychosocial interventions for the ASD population, both these stages of research are required (Smith et al., 2007). 
First we aimed to test the effectiveness of the programme. It was primarily hypothesized that participants would score higher in an interpersonal problem-solving task at post-treatment and that parent-reported socialisation skills and self-reported work personality profiles would score higher compared to pre-treatment. Knowing that the AS population performs significantly worse than typically developed people, the following hypothesis was that the AS group's performance would increase after treatment and therefore the differences between the two groups would decrease at post-treatment in the outcome measures. Secondly, we aimed to evaluate the feasibility of the current intervention based on attrition, treatment adherence (percentage of attendance) and fulfilment of homework. Furthermore, positive reports in consumer satisfaction questionnaires along with parent and participant reports on the maintenance of changes were expected 3 months later.

\section{Method}

\section{Participants.}

Data for a group of 50 adolescents and adults with Asperger syndrome -AS group- were included (43 men and 7 women). The participants' ages ranged from 16 to 29 years and their global IQ was within the limits of normality $(M=96.26 ; S D=16.13$; NV-IQ standard scores: $M=47.96 ; S D=11.45)$ measured by the Reynolds Intellectual Screening Test (RIST; Reynolds and Kamphaus, 2003). The following criteria were observed in the selection process: (a) All the participants presented an earlier diagnosis of Asperger syndrome (DSM-IV-TR criteria; American Psychiatric Association, 2000) which was confirmed by the chief researcher; (b) all participants fulfilled the minimum criteria of Autism Diagnostic Interview-Revised (ADI-R; Rutter et al., 1994) and the Autism Diagnostic Observation Schedule-Generic (ADOS-G; Lord et al., 2008) for 
ASD; and (c) exclusion criteria were also followed for comorbid major psychiatric disorders including ADHD, OCD or other disorders, learning disability or any history of illness or injury involving the brain. Assessments were conducted before and after intervention (pre- and post-treatment) and a questionnaire on the maintenance of changes was answered three months later. See Figure 1 for the flow diagram.

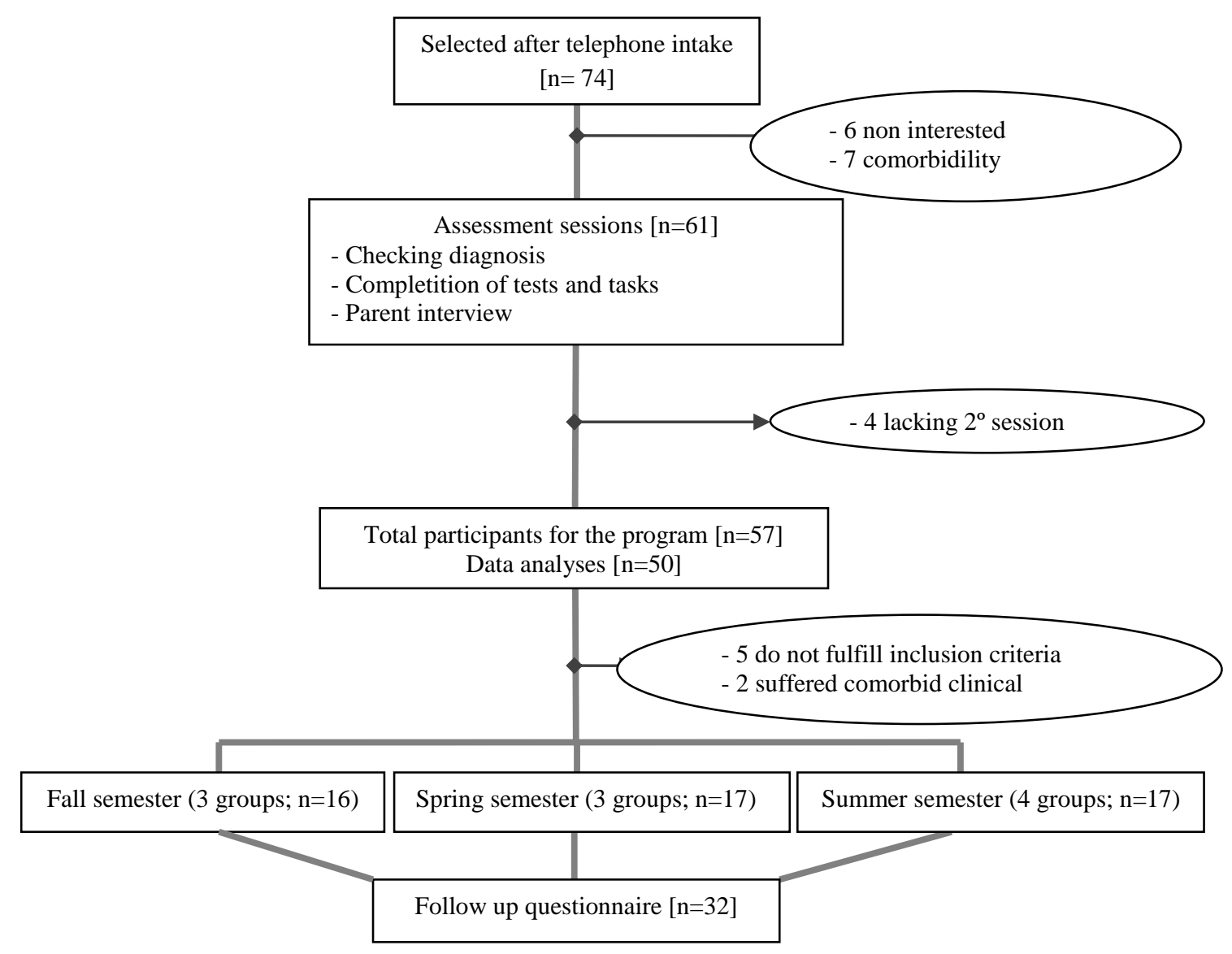

Fig 1. Flow of participants through the clinical trial

Only $14 \%$ of the participants had been diagnosed before five years of age. $48 \%$ were diagnosed before 15 years of age and $38 \%$ during adulthood. With regard to intervention, $48 \%$ had received early intensive intervention during infancy, while $52 \%$ had no experience of any kind in social skills therapy. 
Criteria for outcome was included to rate functionality based on Cederlund et al. (2008). 21 participants (42\%) were classified as having a good outcome (conditions to fulfill this level included both being employed, having achieved higher education or vocational training and living independently or having a group of friends), 22 participants (44\%) were assigned a fair outcome (because of their high education or having at least one close friend) but 7 participants (14\%) lacked both of these characteristics. Measures to rate severity of symptoms, the Autism Diagnostic Observation Schedule-Generic, Module IV (ADOS-G; Lord et al., 2008) and the Autonoma Scale for Asperger syndrome and High-Functioning Autism (Belinchón et al., 2005), were used as a symptomathology screening tool and the Children's Communication Checklist (CCC-2; Bishop, 2003) was used as a measure of pragmatic language (Spanish translation). Table 1 presents the mean symptom severity characteristics of the AS group.

Table 1. Mean symptom severity characteristics of AS group.

\begin{tabular}{ccc}
\hline Variable & Mean & SD \\
\hline ADOS total & 14.06 & 5.13 \\
Autonoma Scale & 53.40 & 6.92 \\
VABS-DB & 17.00 & 7.54 \\
PCI & 44.98 & 10.93 \\
\hline
\end{tabular}

VABS-CD: Disadaptive Behaviour Scale from Vineland Adaptative Behaviour Scales -Second Edition. PCI: Pragmatic Communication Index on CCC-2 
A comparison control group (CG) was included. Composed of student volunteers, they were recruited from two high schools and different degree courses at the University of XXXXXXX, through an open invitation letter or e-mail (this was sent to parents for students under 18). Upon confirmation by students and their parents, there was a randomoly selected group consisted of 50 typically developing participants and matched the gender ratio of the AS group (43 men and 7 women), age $(M=19.54 ; S D=3.46)$ and non verbal IQ standard scores $(M=51.62$ y $S D=9.35)$. Participants had no history of injury or illness involving the brain. No differences were found in educational level compared with the AS group [Fisher (3, $\mathrm{n}=100)=4.01, p=0.279, V$ de Cramer=.203].

\section{Procedure}

Following approval by the University Research Ethics Committee, consent was obtained prior to any data collection. As part of a research project, members of Asperger syndrome Associations in various Spanish cities were encouraged to participate voluntary. For the AS group, assessment was carried out individually in two sessions in their local building prior to the treatment. The first focused on the application of the ADOS-G diagnostic interview, and the second on the remaining tasks. During the same period, parents were convened to make an independent and individual assessment of diagnostic confirmation by means of the ADI-R and to provide information for the VABS-S. After treatment, there was a final group session for assessment on the 
outcome measures (ESCI and O-AFP) and, during the same week, a short interview with the parents took place.

Data on social functioning of the group participants were taken before treatment (pre-treatment) and immediately after completion of the group treatment (posttreatment). A follow up questionnaire was completed 3 months later. Ten AS groups were held over an academic year. Each group included between four and six participants with ASD. One year after the training intervention a feedback session was organised for participants and individualised reports were delivered.

The CG was assessed during an individual session in their own school or at the Clinic of Psychology at the University of XXXXXXX. Parents were contacted by phone to answer the VABS-S. There was no intervention for the CG. Results were used for sample comparisons. All assessments were carried out by the first author, a trained psychologist experienced in working with people with ASD.

\section{Treatment intervention}

The principal investigator was trained on mediation approach during the pilot study. Training consisted of two regular meetings per week with the first author of the programme manual. Group therapy sessions were carried out by the principal investigator. 


\section{Program}

In general terms, the intervention consisted of 75-minute sessions, delivered once a week over a 10-week period to groups of 4-6 people with ASD assisted by a therapist. Being a programme specifically developed for the ASD population, it takes into account particular difficulties and strengths of this population. A mediational approach was adopted for learning, the therapist's aim was to provide the participants with the necessary clues to understand and verbalise, session by session, the phases regarding the solution of interpersonal problems. Through sequential training in a cognitive and metacognitive process, the programme focuses on the interpersonal problem-solving process by working on a phase during each session: 1) Introduction to interpersonal problem-solving skills and description of Asperger syndrome's characteristics; 2) Conversational skills; 3) Defining a problem; 4) Different points of view; 5) Thinking of causes; 6) Generating solutions; 7) Considering consequences and choosing the best option; 8) Plan of action; 9) Evaluating actions and facing failures; 10) Reviewing the process. The content of each session focuses on one particular phase of the process supported by examples on common interpersonal problems that take place in a work environment in combination with participant personal experiences. Appendix A provides an overview of the 10-session intervention. At the end of each session, two homework tasks were given concerning the step by step resolution of two interpersonal problems. They related to short narratives involving an interpersonal 
problem (in a workplace context) to be solved in phases (see Appendix B). At the end of the programme, participants received a portfolio with their homework and a few templates for new interpersonal problem situations to be added as needed in the future.

\section{Subject involvement}

Therapist recorded assistance and homework completion after each individual session rated as follows: $1=$ empty, $2=$ partially completed, $3=$ completed.

\section{Subject satisfaction}

At the final session of assessment, following the treatment, adolescents were asked to rate their satisfaction with the programme on a Likert scale ranging from 1 (no change) to 4 (very clear change), rating the programme as a whole and providing personal comments on what they liked the most and what could be changed. Scores ranged between 12 and 48.

\section{3 month- follow up questionnaire}

An independent questionnaire was sent by post to parents and participants. It was composed of 12 items on a Likert scale of 0 (never) to 4 (a lot) referring to the steps trained during the programme, the utility of the portfolio and the observed changes in relationships. Two items focused on the social validation of the programme. 


\section{Measures}

Due to the lack of "gold-standard" outcome measures (Cunningham, 2012), measures not specifically designed for the AS population were used in this study.

The Assessment of Social Problem-Solving task (ESCI [Evaluación de Solución de Conflictos Interpersonales]; Calero et al., 2009] consists of 12 sequences of images representing an interpersonal conflict, shown on the computer. Participants are required to give written answers to the following questions: 1) How does the principal character in the drawing feel? 2) Why does he/she feel this way? 3) What could he/she do to improve this situation? The task provides a total score and a score for each dimension: Emotion (ESCI-E), Situational Concordance (ESCI-C) and Solutions (ESCI-S). The instrument has been validated in a sample of adolescents from Granada, Spain (Molinero, 2010). As for reliability, a Cronbach index of over $\alpha=.57$ was obtained for each area, while the analyses of factorial validity revealed 6 independent factors in the area of Emotions, 6 in Situational Concordance and 5 in Solutions. It was used as the primary outcome measure.

The Vineland Adaptative Behaviour Scales - Second Edition (VABS; Sparrow et al., 2005) is designed to measure adaptive behaviour in subjects up to 90 years old, on the basis of a report with a Likert-type scale completed by parents or informers. For this study, only two subscales were considered to be relevant: Socialisation area (VABS-S) and Disadaptive Behaviour (VABS-DB; included for symptom severity description). 
The first explores domains of interpersonal relations (VABS-S-Relations), leisure and free time (VABS-S-Leisure) and coping skills (VABS-S-Coping), while the second provides a general index relating to internalised and externalised disadaptive behaviour. The reliability assessment included an analysis of internal consistency for the total score (.93-.97) for different age-groups, test-retest analysis (.76-.92) and inter-rater analysis (.73-.76) for the different domains, subdomains and ages. Content, construct, factorial and criterion validity were confirmed with respect to the earlier version, The Vineland Adaptive Behaviour Scale (.69-.96) and The Adaptive Behaviour Assessment SystemSecond Edition (ABAS-II = .70) (Sparrow et al., 2005).

The Osnabrïck Ability to Work Profile (O-AFP; Wiedl and Uhlhorn, 2006). The O-AFP German scale represents an adaptation of Bolton and Roessler's (1986) Work Personality Profile. In order to explore its use, a Spanish translation of the German scale version was elaborated for the assessment of work capabilities at programme intake and at programme termination. It consists of 30 items using a Likert-type scale. Assessment was carried out by the participant's supervisor and self-reports. The scale ranges from 1 (total lack of skill) to 4 (always present). Assessment of rehabilitants was performed on three subscales, each with 10 items: learning ability (LA), social communication and interactional competence (SIC), and social adaptation and motivation (SAM). Internal consistency for the German scales were $\alpha=.954$ for LA, 0.909 for SIC and .899 for SAM. 


\section{Statistical analysis}

This was an open trial for an intervention of a structured interpersonal problemsolving implementation in group format. Due to its implementation in community settings participants were selected through convenience sampling (Lucas, 2013). To evaluate changes after treatment in the outcome measures (interpersonal problemsolving, parents' reports on social skills and work capabilities), a one-way repeated measures ANOVA was conducted to compare scores on the outcome measures in pretreatment and post-treatment within the AS group and the effect sizes were reported (Cohen $d^{\prime}$ ). Clinical significance or magnitude of each subject's change was determined by Computing Reliable Change Indices (RCI; Jacobson and Truax, 1991). Based on this model, change scores greater than 1.96 were considered statistically significant and clinically meaningful. Finally, pre-treatment and post-treatment scores for the AS group were compared to the $\mathrm{CG}$ in order to explore the decrease in effect sizes (Cohen $d$ ) following treatment. Inter-group $t$-test analyses were carried out for the different static measures. Results from the test statistic, $p$ (two tails) and effect sizes are reported (Fild, 2009).

Feasibility was explored by calculating attrition, treatment adherence based on percentage of attendance, fulfilment of homework and reports in participant satisfaction questionnaires completed by participants and parents (rating how helpful was the intervention). 


\section{Results}

\section{Changes after treatment}

The means, standard deviations and effect sizes in the outcome measures are presented in table 2 (Greenhouse-Geisser correction). Significant differences were found in the socialisation total scale (VABS-S) $[F(1,49)=61.13, p<0.0001]$ and subscales VABS-Relations $[F(1,49)=136.29, p<0.005]$, VABS-Leisure $[F(1,49)=15.39$, $p<0.005]$ and VABS-Coping $[F(1,49)=97.38, p<0.005]$ in the social problem-solving task total score $($ ESCI-Total) $[F(1,49)=43.92, p<0.0001]$, Situational Concordance domain $($ ESCI-C) $[F(1,49)=15.51, p<0.0001]$ and Solutions domain $($ ESCI-S) $[F(1$, $49)=35.27, p<0.0001]$. Emotion domain was not significant. For the Osnabrück Ability to Work Profile, only the Learning subscale self-report version showed significant higher scores after intervention $[F(1,47)=10.01, p=0.003]$ but a small effect size. Effect sizes were large for VABS-S Total, ESCI-C and ESCI-S.

Table 2. Pre-treament, Post-treatment and effect size in outcome measures.

\begin{tabular}{|c|c|c|c|}
\hline & $\begin{array}{l}\text { AS Group } \\
\text { M (SD) }\end{array}$ & $\begin{array}{c}\text { CG } \\
M(\mathrm{SD})\end{array}$ & $\begin{array}{c}\text { Effect size* } \\
\text { (between groups }\end{array}$ \\
\hline \multicolumn{4}{|l|}{ VABS-S Total } \\
\hline Pre & $155.63(11.29)$ & $191.7(3.97)$ & 3.01 \\
\hline Post & $167.92(12.84)$ & & 1.77 \\
\hline Effect size & 0.555 & & \\
\hline \multicolumn{4}{|l|}{ VABS-S Relations } \\
\hline Pre & $61.26(3.23)$ & $74.50(1.16)$ & 3.85 \\
\hline Post & $65.78(3.31)$ & & 2.48 \\
\hline Effect size & 0.736 & & \\
\hline \multicolumn{4}{|l|}{ VABS-S Leisure } \\
\hline Pre & $51.81(4.14)$ & $60.82(1.42)$ & 2.05 \\
\hline
\end{tabular}




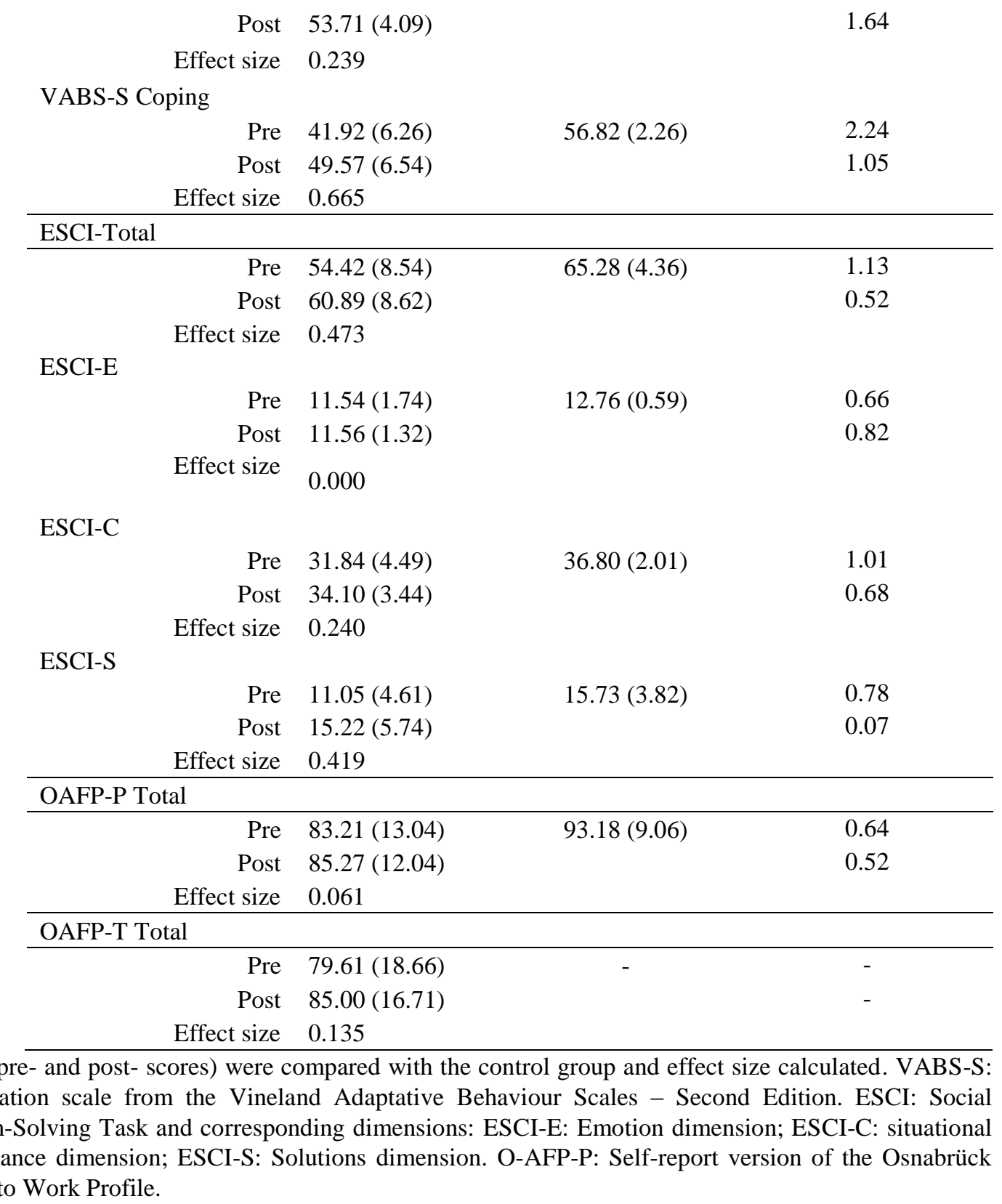

Statistically, significant change was expected for individual scores in outcome measures. 25 of the 50 participants (50\%) showed statistically significant change 
$(\mathrm{RCI}>1.96)$ for at least one area of the social problem-solving task (ESCI-E, ESCI-C or ESCI-S). On the socialisation skills reported by parents (VABS-S) 21 of the 50 participants (42\%) obtained statistically significant change. A total of 15 of the 50 participants (41\%) showed significant change on the ESCI and the VABS-S simultaneously. Two participants $(4 \%)$ showed RCI $>1.96$ on the work personality profile (O-AFP) self-report while only one participant $(2 \%)$ on the O-AFP tutor report.

In order to test decreasing effect sizes, comparing the sample with task performance of a control group, $t$ test comparisons were calculated for both groups pre-treatment and post-treatment. The effect sizes based on post-treatment scores were compared with the effect sizes found at baseline for the AS group compared with the CG (see table 2). Values diminished in all cases except for ESCI-E (see figure 2).

$<$ Insert Figure 2 >

Fig 2. Effect sizes of differences between AS group (pre- and post-treatment) and CG

\section{Feasibility}

Generally, 48 out of 50 participants (96\%) completed the intervention. Only 2 of the 50 participants dropped out due to reasons unrelated with the programme. The overall rate of attendance (a total of 110 sessions, 10 groups $* 11$ sessions - including the 
final assessment-) for the 50 participants was $70 \%$; the range per participant was $6 \%$ (1 session) to $100 \%$ (11 sessions). 2 participants (4\%) dropped out during the first sessions. 24 participants (48\%) attended all sessions, 19 participants (32\%) missed one session and 7 participants (10\%) missed more than one session. Based on the benchmarks of $70 \%$ for overall attendance, these attendance rates were considered satisfactory to indicate that the families adhered to the treatment programme (White et al., 2010).

Participant compliance with homework assignments, defined as at least partially completed between-session assignments, ranged from 20 to $100 \%$ across participants (mean compliance $=87 \%$ ). The lowest rate of homework completion was for the phase concerning session 9 (Dealing with failure), which required filling out the handout for the given situation which included a section of self-assessment based on a group roleplay at the beginning of session 10. Session 5 seemed to be the second most difficult task based on compliance which was specifically focused on Detecting causes of problems.

The parents of the 32 participants completed the Programme Satisfaction Survey (this questionnaire was not offered to the first three groups run). In general, participants seemed to be satisfied with what they learned from the programme $(M=33.74, S D=$ 11.48). The highest score was for items "I get on better with my group peers", "I learnt to think about what could be the causes of negative feelings in others or problems" and "I am more conscious to pay attention to others' feelings". The item with the lowest 
rate was "Now, I start more conversations about topics which are interesting for others even if they are not for me".

48 participants and 47 parents answered the 3 month follow up questionnaire. As a group, participants reported a medium change (a score of 3) on the majority of items except for 'Having a written plan of action helps me to cope with interpersonal problems, Using the portfolio to solve problems and Family interactions have become better'. However, change was reported for better relations with friends and less problems with others. In general, all parents reported that they observed change on items such as 'Solving problems more efficiently, Better definition of problems, Family interactions have become better, better reactions with friends and less problems with others'. Some change (scoring 2) was also reported for 'Improving in generating solutions, thinking about consequences before acting'. $100 \%$ of participants and parents agreed that intervention should be funded by a public or private enterprise and all of them recommended the programme for someone with their condition. Summarising the participants' responses to the open-ended questions, most parents reported feeling that the programme was too short and more sessions would have improved outcomes. Furthermore, they said that a simultaneous guide for parents would have been useful to continue practicing with their children at home. Participants agreed that homework tasks were hard to do but were needed to improve their knowledge in the interpersonal problem-solving process. 


\section{Discussion}

This study begins to address the issue of intervention in interpersonal problemsolving skills for a well-defined sample of young adults with AS, through sequential training in a cognitive and metacognitive process across ten weekly sessions. The goals were to examine treatment effectiveness and feasibility.

Analysis of treatment effectiveness was based on changes in participants' performance of a social problem-solving task (primary outcome measure) and parent and tutor reports (secondary outcome measures). The initial hypothesis was confirmed, the AS group showed significant improvements after treatment in ESCI (Situational Concordance and Solution dimensions) and VABS-S. Participants also reported changes in the Learning subscale of the Ability to Work Profile. Moreover, analyses of RCI showed significant changes individually. 25 participants showed statistically significant change in the social-problem-solving task. Also, parents reported significant change in 15 of them based on the VABS-S. Two of these "responders" simultaneously reported changes in work capabilities. Thus, using a more conservative method (RCI), positive effects of the treatment were also detected. Although interpretation needs to be attentive as statistically significant change does not necessarily equate positive change that is personally meaningful to the client and worth the costs associated with the treatment (Kraemer et al., 2006). Further research is critical to determine if changes do generalise out of sessions.Follow up reports after 3 months pointed to some changes being 
maintained in social problem-solving areas. The AS group scores pre- and posttreatment were compared with the CG performances and the effect's sizes were reported in order to examine the decrease in differences with the $\mathrm{CG}$ after treatment. The general pattern indicated that the differences between the AS group and the CG decreased after treatment. Thus, using a variety of methods, significant changes were found after treatment.

Qualitative data supported the feasibility of the SCI-Laboral programme. Attendance of the group was quite satisfactory. General attendance was $70 \%$, a value which meets the minimum required for a clinical trial (White et al., 2010) and only two participants dropped out for reasons out of the programmes control. The average homework completion rate by the adolescents in this trial was higher than the compliance reported in previous psychoeducational interventions with adolescents, which have indicated that participants complete only approximately half of assigned between-session tasks (Gaynor et al., 2006; White et al., 2012). These results may indicate high motivation among adolescents and adults who are concerned about their impairments and would like to face possible employment. During the feedback session one year later participants and parents highlighted the lack of long-term social support or training interventions for youngsters with Asperger syndrome. 


\section{Limitations}

Amongst the limitations of the study, we should mention the specific content of the programme which is focused on interpersonal-problem solving skills trained in group format. Therefore it is not a comprehensive treatment nor completely individualised. Secondly, motivation was different amongst participants and their parents which may have influenced treatment improvements. Another possible limitation concerns the lack of an independent evaluator who would be blind to the treatment process. Possible violations might have been compensated for by the quality of most of the measures applied. Moreover, the training showed consistency delivered by one single therapist. It was not influenced by personal factors by different trainers which assures a higher degree of integrity to the manual during the treatment process. Also, randomised group assignments were not controlled for comparison with waiting list group which limitates generalitation of conclusions. However, having provided a program delivered in community settings for a unique population, results are still suitable for answering needs of adulthood population with Asperger syndrome (Small, 2009). Furthermore, the lack of "gold-standard" measures to evaluate treatment outcomes meant that new measures were used with the AS population for the first time (ESCI and O-AFP).

Social problem-solving skills are frequently impaired in the ASD population. The ability to properly address interpersonal problems is especially required during 
adolescence and adulthood as it is a critical period for employment development. However, research evidence focused on this type of intervention is still at a very young stage.

\section{Conclusion}

This study represents one of the largest intervention samples for adolescents with AS recruited in this country. This study describes the development of a treatment programme specifically designed for young people affected by AS and effectiveness and feasibility data are presented. Collected data shows that participants' performance increase after treatment. Results are promising, indicating that the programme was acceptable to consumers and that it could be delivered in community settings and attended by general clients. Further research should study efficacy of the training based on maintenance of change, generalisation to untaught behaviours and randomised control trials or wait-list group assignments (Smith et al., 2007).

In conclusion, this study represents a novel contribution in terms of the evaluation of treatment effects based on a manual program specifically developed for people affected by ASD. 


\section{Appendix A.}

Outline of the content of the SCI-Labour Programme

\begin{tabular}{|c|c|c|}
\hline Session & Didactic lesson & Content of the session \\
\hline 1. & Introduction & $\begin{array}{l}\text { Interpersonal problem-solving skills can be trained. } \\
\text { Description of Asperger Syndrome's characteristics. }\end{array}$ \\
\hline 2. & Conversational skills & $\begin{array}{l}\text { Importance of listening. Starting and maintaining conversation. } \\
\text { Asking questions. }\end{array}$ \\
\hline 3. & $\begin{array}{l}\text { Identifying and defining a } \\
\text { problem }\end{array}$ & $\begin{array}{l}\text { Participating. Following instructions. Looking for "clues" to } \\
\text { discover a problem. Personal problems vs. interpersonal problems. } \\
\text { Defining problems. }\end{array}$ \\
\hline 4. & Different points of view & $\begin{array}{l}\text { Detecting and expressing your own feelings. Understanding other's } \\
\text { feelings. Changing perspectives. Expressing affection. }\end{array}$ \\
\hline 5. & Thinking of causes & $\begin{array}{l}\text { Influence of different factors on an interpersonal problem. } \\
\text { Collecting information about causes. Different causes of problems. }\end{array}$ \\
\hline 6. & Generating solutions & Generating different solutions. Making decisions. \\
\hline 7. & $\begin{array}{l}\text { Considering consequences } \\
\text { Choosing the best option }\end{array}$ & $\begin{array}{l}\text { Examining consequences for each solution. Consequences based on } \\
\text { time vs. consequences based on severity. }\end{array}$ \\
\hline 8. & $\begin{array}{l}\text { Plan of action. Detecting } \\
\text { obstacles }\end{array}$ & $\begin{array}{l}\text { Developing a plan of action for the chosen solution. Looking for } \\
\text { possible obstacles and factors influencing the final result. }\end{array}$ \\
\hline 9. & $\begin{array}{l}\text { Evaluating actions and } \\
\text { facing failures }\end{array}$ & $\begin{array}{l}\text { Assessing results. Feedback. Dealing with failure through concrete } \\
\text { actions and feelings. }\end{array}$ \\
\hline 10. & Reviewing the process & $\begin{array}{l}\text { Going through the whole resolution process. Applying the full } \\
\text { handout to a personal situation for each participant and share it with } \\
\text { the group. }\end{array}$ \\
\hline
\end{tabular}


Appendix B. An example of one of the homework task which includes a typical situation at the workplace where an interpersonal problem needs to be solved. Steps of resolution must be completed by the participant.

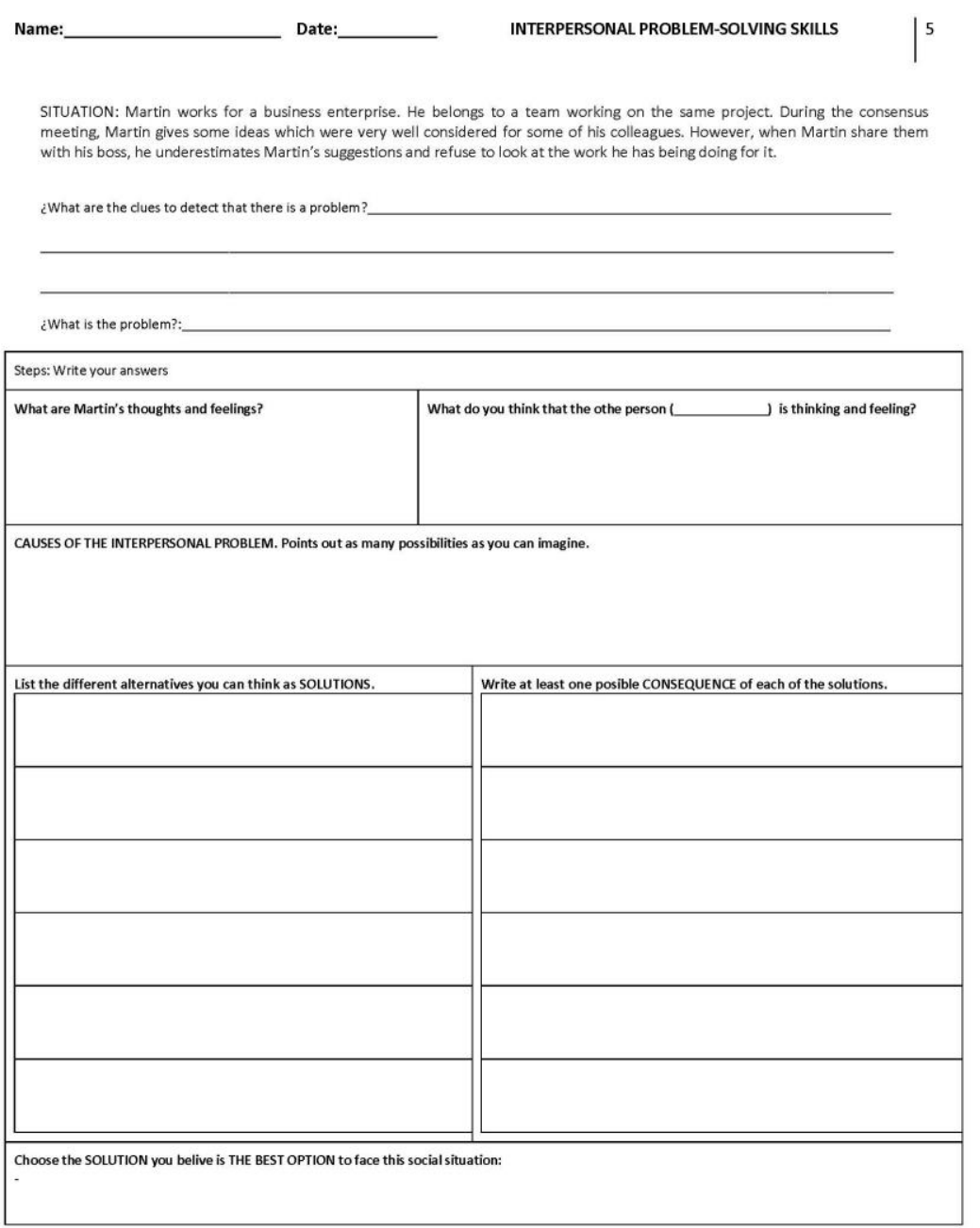




\section{REFERENCES}

American Psychiatric Association (2000) Diagnostic and statistical manual of mental disorders ( $4^{a}$ ed. revised.). Washington, DC: autor.

Anderson, KA, Shattuck, PT, Cooper, BP, Roux, AM and Wagner, M (2013)

Prevalence and correlates of postsecondary residential status among young adults with an autism spectrum disorder. Autism, DOI:10.1177/1362361313481860

Antshel, KM, Polacek, C, McMahon, M, Dygert, K, Spenceley, L, Dygert, L, Miller, L and Faisal, F (2011). Comorbid ADHD and anxiety affect social skills group intervention treatment efficacy in children with autism spectrum disorders. Journal of Developmental and Behavioral Pediatrics, 32 (6): 439-46.

Baron-Cohen, S, Golan, O, Wheelwright, S and Hill, JJ (2004) Mind reading: The interactive guide to emotions. London: Jessica Kingsley Limited.

Belinchón, M, Hernández, JM, Martos, J, Sotillo, M, Márquez, J and Olea J (2005) Escala Autónoma para la detección del síndrome de asperger y el autismo de alto nivel de funcionamiento. En M Belinchón, JM Herández, y M Sotillo (2008) Personas con Síndrome de Asperger. Funcionamiento, detección y necesidades. Madrid: Centro de Psicología Aplicada de la UAM, Confederación Autismo España, FESPAU y Fundación ONCE.

Bishop, DVM (2003) The Children's communication checklist. CCC-2 Manual. Second Edition. London: Harcourt Assessment.

Bonete, S (2013) Impacto del entrenamiento de habilidades interpersonales para la adaptación laboral en jóvenes con Síndrome de Asperger. Doctoral thesis. University of Granada, Spain.

Calero, MD., García-Martín, B, Molinero, C y Bonete, S (2009) Evaluación de Solución de Conflictos Interpersonales, ESCI [not published]. University of Granada, Spain. 
Carter, A, Davis, N, Klin, A and Volkmar, F (2005) Social development in autism. In FR Volkmar, R Paul, A Klin, \& D Cohen (Eds.), Handbook of autism and pervasive developmental disorders (3rd ed., pp. 312-334). Hoboken, NJ: John Wiley.

Cederlund, M, Hagberg, B, Billstedt, E, Gillberg, IC and Gillberg, C (2008) Asperger syndrome and autism: A comparative longitudinal follow-up study more than 5 years after original diagnosis. Journal of Autism and Developmental Disorders, 38: $72-85$.

Chang, EC, D' Zurilla, TJ and Sanna, LJ (2009) Social Problem Solving as a Mediator of the Link Between Stress and Psychological Well-being in Middle-Adulthood. Cognitive Therapy and Research, 33 (1): 33-49.

Chang Y, Laugeson, EA, Gantman, A, Ellingsen, R, Frankel, F and Dillon, AR (2013) Predicting treatment success in social skills training for adolescents with autism spectrum disorders: The UCLA Program for the Education and Enrichment of Relational Skills. Autism, DOI: 10.1177/1362361313478995

D’Zurilla, TJ and Goldfried, MR (1971) Problem solving and behavior modification. Journal of Abnormal Psychology, 78: 107-126.

Fild, A (2009) Discovering statistics using SPSS. London: SAGE Publications

Gantman, A, Kapp, SK, Orenski, K and Laugeson, EA (2012) Social skills training for young adults with high-functioning autism spectrum disorders: A randomized controlled pilot study. Journal of Autism and Developmental Disorders, 42 (6): 1094-103.

García-Villamisar, D and Hughes, C (2007) Supported employment improves cognitive performance in adults with Autism. Journal of Intellectual Disability Research, 5 (2):142-50.

Gaynor, ST, Lawrence, PS, and Nelson-Gray, RO (2006) Cognitive-behavioral therapy for adolescent depression: Review, preliminary findings, and implications for theory and practice. Behavior Modification, 30: 647-672. 
Happé, F and Charlton, RA (2012) Aging in autism spectrum disorders: a mini-review. Gerontology, 58(1): 70-8.

Hare, DJ, Pratt, C, Burton, M, Bromley, J and Emerson, E (2004) The health and social care needs of family carers supporting adults with autistic spectrum disorders. Autism, 8(4): 425-44.

Haywood, HC and Lidz, CS (2007). Dynamic assessment in practice: Clinical and educational applications. NY: Cambridge University Press.

Hops, H (1983) Children's social competence and skill: Current research practices and future directions. Behavior Therapy, 14(1): 3-18.

Howlin, P and Moss, P (2012) Adults With Autism Spectrum Disorders. Canadian Journal of Psychiatry. Revue Canadienne de Psychiatrie, 57(5): 275-283.

Jacobson, NS and Truax, P (1991) Clinical Significance : A Statistical Approach to Defining Meaningful Change in Psychotherapy Research. Journal of Consulting and Clinical Psychology, 59(1): 12-19.

Kozulin, A and Rand, Y (2000) Experience of mediated learning. An impact of Feuerstein's theory in education and psychology. Oxford: Elsevier Science Ltd.

Kraemer, H, Minitz, J, Noda, A, Tinklenberg, J, and Yesavage, JA (2006) Caution regarding the use of pilot studies to guide power calculations for study proposals. Archives of General Psychiatry, 63: 484-489.

Laugeson, E, Frankel, F, Gantman, A, Dillon, AR and Mogil, C (2012) Evidence-based social skills training for adolescents with autism spectrum disorders: the UCLA PEERS program. Journal of Autism and Developmental Disorders, 42 (6): 1025-36.

Leshner, A, Shelley, R, Kern, RS (2013) Errorless learning and social problem solving ability in schizophrenia: an examination of the compensatory effects of training. National Library of Medicine. Psychiatry Research, 206, (1): 1-7.

Lord, C, Rutter, M., DiLavore, P and Risi, S (2009) ADOS. Escala de observación para el diagnóstico del autismo. Spanish adaptation by Nanclares-Nogués, V and Santamaría Fernández, P. Madrid: TEA Ediciones, S.A. 
Lucas, SR (2013) Beyond de existence proof: ontological conditions, empistemological implications, and in-depth interview research. Quality \& Quantity, DOI: 10.1007/s11135-012-9775-3

Mazefsky, CA and White, SW (2013) Adults with autism. En SJ Rogers (Ed.), Handbook of autism spectrum disorders $\left(4^{\text {th }}\right.$ Ed.). Hoboken, NJ: Wiley and Sons.

Molinero, C (2010) Estudio psicométrico de la prueba de solución de conflictos interpersonales (ESCI). Master de Metodología de las Ciencias del Comportamiento y la Salud. Universidad de Educación a Distancia, UNED.

Morgan, RL and Schultz, JC (2012) Towards an ecological, multi-Modal approach to increase employment for young adults with autism spectrum disorder. Journal of Applied Rehabilitation Counseling, 43(1): 27-35.

Nezu, AM, Nezu, CM and Jain, D (2008). Social problem solving as a mediator of the stress-pain relationship among individuals with non-cardiac chest pain. National Library of Medicine. Health psychology: Official Journal of the Division of Health Psychology, American Psychological Association 27 (6): $829-832$

Parr, AD and Hunter, ST (2013). Enhancing work outcomes of employees with autism spectrum disorder through leadership: Leadership for employees with autism spectrum disorder. Autism: The International Journal of Research and Practice. DOI: $10.1177 / 1362361313483020$

Pelechano, V (1995) Habilidades interpersonales: conceptualización y entrenamiento. In MD Calero (1995). Modificación de la inteligencia: Sistemas de evaluación e intervención (pp. 131-179). Madrid: Pirámide.

Reynolds, CR and Kamphaus, RW (2009). RIAS. Escalas de inteligencia de Reynolds y test de inteligencia breve de Reynolds. RIST. Spanish adaptation by Santamaría Fernández, P and Fernández Pinto, I. Madrid: TEA Ediciones, S. A.

Small, ML (2009) “ 'How many cases do I need?' On science and logic of case selection in field-based research" Ethnography, 10:5-38. 
Smith, T, Scahill, L, Dawson, G, Guthrie, D, Lord, C, Odom, S, Rogers, S and Wagner, A (2007) Designing research studies on psychosocial interventions in autism. Journal of Autism and Developmental Disorders, 37: 354-366.

Sparrow, SS, Cicchetti, DV and Balla, DA (2005) Vineland-II. Adaptative behaviour scales: Survey forms manual. Circle Pines, MN: AGS Publishing.

Weiss, JA and Lunsky, Y (2010) Report Behaviour Therapy for Adults with Asperger syndrome and Anxiety or Mood Disorder : A Case Series. Clinical Psychology \& Psychotherapy, 446: 438-446.

White, SW, Keonig, K and Scahill, L (2010) Group Social Skills Instruction for Adolescents With High-Functioning Autism Spectrum Disorders. Focus on Autism and Other Developmental Disabilities, 25(4): 209-219.

White, SW, Ollendick, T, Albano, AM, Oswald, D, Johnson, C, Southam-Gerow, MA, Kim, I, et al. (2012) Randomized Controlled Trial: Multimodal Anxiety and Social Skill Intervention for Adolescents with Autism Spectrum Disorder. Journal of Autism and Developmental Disorders. DOI:10.1007/s10803-0121577-x. Published online 27 June

Wiedl, KH and Uhlhorn, S (2006) O-AFP: Osnabrueck Ability to Work Profile [en alemán]. Goettingen, Germany: Hogrefe. 